\title{
Joule Heating and Dissipation Effects on Magnetohydrodynamic Couple Stress Nanofluid Flow over a Bidirectional Stretching Surface
}

\author{
Nainaru Tarakaramu1, Panyam Venkata Satya Narayana ${ }^{1 *}$, Dondu Harish $\mathrm{Babu}^{2}$, Ganganapalli Sarojamma ${ }^{3}$, Oluwole \\ Daniel Makinde ${ }^{4}$ \\ ${ }^{1}$ Department of Mathematics, SAS, VIT, Vellore 632014, T.N, India \\ ${ }^{2}$ Dept. of Mathematics, Sree Vidyanikethan Eng. College, Tirupati 517502, A.P, India \\ ${ }^{3}$ Department of Applied Mathematics, Sri Padmavati Mahila University, Tirupati 517502, AP, India \\ ${ }^{4}$ Faculty of Military Science, Stellenbosch University, Private Bag X2, Saldanha 7395, South Africa
}

Corresponding Author Email: psatya@vit.ac.in

https://doi.org/10.18280/ijht.390122

Received: 23 September 2019

Accepted: 12 November 2020

\section{Keywords:}

magnetohydrodynamic, couple stress, nanofluid, joule heating, viscous dissipation, stretching sheet

\begin{abstract}
This work examines the effects of non-linear thermal radiation and Joule heating on MHD three-dimensional visco-elastic nanofluid flow due to a surface stretching in lateral directions. A coupled nonlinear differential system is generated from the boundary layer equations by using self-similarity variables and is then solved numerically by using most powerful shooting technique with Runge Kutta method of fourth order. The computational results for the flow variables are plotted graphically and are discussed in detail for various governing parameters that emerged in the analysis. It is observed that the momentum of the visco elastic nanofluid is better than that of a viscous fluid. Thicker thermal and concentration boundary layers are formed for increasing nonlinear thermal radiation and temperature ratio parameters. Also the results are in very good agreement with the outcomes available in the literature as a particular case. This model may play a significant role in the field of manufacturing and engineering applications.
\end{abstract}

\section{INTRODUCTION}

Nowadays, many researchers have been attracted towards the study in MHD viscoelastic (biological solutions, colloids, asphalts, glues, tars, paints, and fluids contain melts of polymer) nanofluid flows in view of their diverse scientific applications. Thermal and concentration boundary layer flow of a viscoelastic fluid over a stretching sheet was presented numerically by Ashraf et al. [1], and Mohamed et al. [2]. NonNewtonian nanofluid flow due to polymeric stretching sheet in the presence of dissipation and surface transpiration was devoted by Rana et al. [3]. They reported that their analysis finds applications in the manufacturing process of rheological nano-bio-polymers. Seth et al. [4] explored the viscoelastic nanofluid flow past a stretching sheet with thermal radiation and soret effects. The influence of Cattaneo-Christov double diffusion in a viscoelastic nanofluid flow has been discussed by Hayat et al. [5]. Recently, some of the researchers [6-12] investigated the viscoelastic nanofluid flow induced due to a sheet stretching.

The influence of Joule heating and non-linear radiation on magnetohydrodynamic nanofluid flow caused due to sheet stretching plays a significant role in the fields of manufacturing and engineering. He et al. [13] developed the fictitious domain method with distributed Lagrange multipliers to study the unsteady flow in a screw extruder. Tarakaramu and Satyanarayana [14] investigated the hydromagnetic nanofluid flow induced by a sheet stretching with chemical reaction. Kumar et al. [15] analysed the 3D flow of non -Newtonian nanofluid in the presence of radiation and Joule heating. Rehman et al. [16] presented the thermo- physical aspects of nanofluid flow induced by a cylindrical stretching surface. Babu and Narayana [17] explored the magnetohydrodynamic non-Newtonian fluid flow induced by sheet stretching with Joule heating. Several researchers [1823] explored $3 \mathrm{D}$ convection flows caused due to a sheet stretching in the presence of Lorentz forces.

The couple stresses [24-26] are non-central forces exerted between particles in a fluid flow. These forces in nanofluid flows play a significant role in several industrial applications (food industry, waste heat recovery, air conditioning, refrigeration and automobile radiators) due to enhanced heat transfer. Also, these fluids are capable of describing different fluid characteristics. The influence of nonlinear thermal radiation on three-dimensional boundary layer flow of a couple stress nanofluid was explored by Hayat et al. [27]. MHD couple stress viscoelastic nanofluid flow induced by a continuously sheet stretching has been analysed by Turkyilmazoglu [28]. The effects of thermal radiation and thermodiffusion on couple stress fluid flow between two vertical parallel plates have been discussed by Kaladhar et al. [29], and Hayat et al. [30]. They presented the influence of heat transfer characteristics of a couple stress nanofluid on a magnetohydrodynamic three-dimensional flow due to bidirectional stretching. Beg et al. [31] presented the oscillatory flow of a non-Newtonian bio-fluid in a rotating channel with Lorentz forces. Hayat et al. [32] presented the three-dimensional magnetohydrodynamic flow of a couple stress nanofluid past a stretching surface. Kumar et al. [33] experimentally developed the $\mathrm{Fe}_{3} \mathrm{O}_{4}$ nanofluid flow through longitudinal strip inserts. Many authors [34-44] considered various mathematical nanofluid flow models to analyse the 
heat transfer aspects. Satyanarayana [45] adopted the lie group analysis to examine the nanofluid flow induced by the sheet stretching.

The main objective of present work is to analyse the magnetohydrodynamic 3D flow of a couple stress fluid in the presence of Joule heating and non-linear thermal radiation. The governing boundary layer equations are converted to a system of coupled ODEs by using the similarity variables. The transformed system can be solved numerically by RKF scheme with shooting method. Expressions for various values of parameters on the flow field and other aspects are discussed graphically and numerically.

\section{MATHEMATICAL FORMULATION}

Three dimensional hydromagnetic flow of an incompressible electrically conducting visco-elastic couple stress nanofluid induced by a bidirectional stretching sheet is considered in this mathematical model. A constant Lorentz force is applied on the fluid normal to the flow direction. Choose a Cartesian coordinates system $(x, y, z)$ in which $x$ - and $y$ - axes are along the lateral directions of the stretchable surface and $\mathrm{z}$ - axis is normal to it. The fluid flow occurs for $z>0$ as displayed in Figure 1. The stretching components of velocities along $x$ and $y$ directions are respectively defined as $A=a x$ and $B=b y$. Joule heating, dissipation and nonlinear thermal radiations are considered in the energy equation. Using the above assumptions, the equations of continuity, momentum, energy and species concentration are as follows

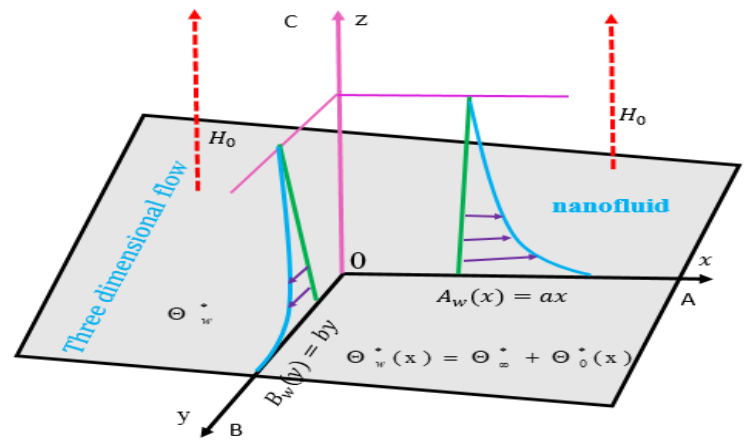

Figure 1. Physical model and configuration

$$
\left.\begin{array}{c}
\frac{\partial A}{\partial x}+\frac{\partial B}{\partial y}+\frac{\partial C}{\partial z}=0 \\
A \frac{\partial A}{\partial x}+B \frac{\partial A}{\partial y}+C \frac{\partial A}{\partial z}=v \frac{\partial^{2} A}{\partial z^{2}}-v^{\prime} \frac{\partial^{4} A}{\partial z^{4}}-\frac{\sigma H_{0}^{2}}{\rho_{f}} A \\
A \frac{\partial B}{\partial x}+B \frac{\partial B}{\partial y}+C \frac{\partial B}{\partial z}=v \frac{\partial^{2} B}{\partial z^{2}}-v^{\prime} \frac{\partial^{4} B}{\partial z^{4}}-\frac{\sigma B_{0}^{2}}{\rho_{f}} B \\
A \frac{\partial \Theta}{\partial x}+B \frac{\partial \Theta}{\partial y}+C \frac{\partial \Theta}{\partial z}=\alpha \frac{\partial^{2} \Theta}{\partial z^{2}}-\frac{1}{\left(\rho c_{p}\right)_{f}} \frac{\partial q_{r}}{\partial z} \\
+\xi\left(D_{0}\left(\frac{\partial \Psi}{\partial z} \frac{\partial \Theta}{\partial z}\right)^{+}+\frac{D_{\Theta}}{\Theta \infty}\left(\frac{\partial \Theta}{\partial z}\right)^{2}\right)+\frac{\sigma H_{0}^{2}}{\left(\rho c_{p}\right)_{f}}\left(A^{2}+B^{2}\right) \\
+\frac{\mu}{\left(\rho c_{p}\right)_{f}}\left(\left(\frac{\partial^{2} A}{\partial z^{2}}\right)^{2}+\left(\frac{\partial^{2} B}{\partial z^{2}}\right)^{2}\right) \\
+\frac{2 \mu}{\left(\rho c_{p}\right)_{f}}\left(\left(\frac{\partial A}{\partial z}\right)^{2}+\left(\frac{\partial B}{\partial z}\right)^{2}\right)
\end{array}\right\}
$$

$$
A \frac{\partial \Psi}{\partial x}+B \frac{\partial \Psi}{\partial y}+C \frac{\partial \Psi}{\partial z}=D_{0}\left(\frac{\partial^{2} \Psi}{\partial z^{2}}\right)+\frac{D_{\Theta}}{\Theta_{\infty}}\left(\frac{\partial^{2} \Theta}{\partial z^{2}}\right)
$$

The relevant boundary conditions (B.Cs) for this model are

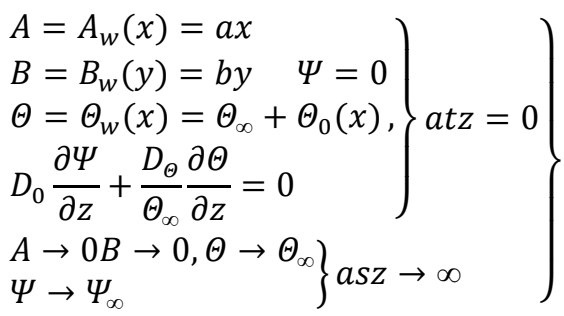

According to the Rosseland's approximation (Brewster [46]), the non-linear radiative heat flux $q_{r}$ is defined as:

$$
q_{r}=-\frac{4 \sigma^{*}}{3 k^{*}} \frac{\partial \Theta^{4}}{\partial z}=-\frac{16 \sigma^{*}}{3 k^{*}} \Theta^{3} \frac{\partial \Theta}{\partial z}
$$

On differentiation we get

$$
\frac{\partial q_{r}}{\partial z}=-\frac{16 \sigma^{*}}{3 k^{*}} \frac{\partial}{\partial z}\left(\Theta^{3} \frac{\partial \Theta}{\partial z}\right)
$$

In view of Eq. (8), Eq. (4), can be written as

$$
\left.\begin{array}{l}
A \frac{\partial \Theta}{\partial x}+B \frac{\partial \Theta}{\partial y}+C \frac{\partial \Theta}{\partial z}=\alpha_{m} \frac{\partial^{2} \Theta}{\partial z^{2}} \\
+\frac{1}{\left(\rho c_{p}\right)_{f}}\left(\frac{16 \sigma^{*}}{3 k^{*}} \frac{\partial}{\partial z}\left(\Theta^{3} \frac{\partial \Theta}{\partial z}\right)\right) \\
+\xi\left(D_{0}\left(\frac{\partial \Theta}{\partial z} \frac{\partial \Theta}{\partial z}\right)+\frac{D_{\Theta}}{\Theta_{\infty}}\left(\frac{\partial \Theta}{\partial z}\right)^{2}\right) \\
+\frac{\sigma H_{0}^{2}}{\left(\rho c_{p}\right)_{f}}\left(A^{2}+B^{2}\right) \\
+\frac{2 \mu}{\left(\rho c_{p}\right)_{f}}\left(\left(\left(\frac{\partial A}{\partial z}\right)^{2}+\left(\frac{\partial B}{\partial z}\right)^{2}\right)\right) \\
+\frac{\mu}{\left(\rho c_{p}\right)_{f}}\left(\left(\frac{\partial^{2} A}{\partial z^{2}}\right)^{2}+\left(\frac{\partial^{2} B}{\partial z^{2}}\right)^{2}\right)
\end{array}\right\}
$$

The suitable similar transformations for this model are

$$
\begin{aligned}
& A=\operatorname{ax} f^{\prime}(\eta), B=\operatorname{ayg}(\eta), C=-\sqrt{a v}(f(\eta)+g(\eta) \\
& \theta(\eta)=\frac{\Theta-\Theta_{\infty}}{\Theta_{w}-\Theta_{\infty}} \phi(\eta)=\frac{\Psi-\Psi_{\infty}}{\Psi_{w}-\Psi_{\infty}} \eta=\left(\frac{a}{c}\right)^{1 / 2} z
\end{aligned}
$$

Using the above Eq. (10), we can recast the Eqns. (2)-(5) and (9) as

$$
\begin{aligned}
& f^{\prime \prime \prime}-K f^{v}-\left(f^{\prime}\right)^{2}-M^{2} f^{\prime}+f^{\prime \prime}(f+g)=0 \\
& g^{\prime \prime \prime}-K g^{v}-\left(g^{\prime}\right)^{2}-M^{2} g^{\prime}+g^{\prime \prime}(f+g)=0 \\
& \left.\begin{array}{rl}
P r\left((f+g) \theta^{\prime}-f^{\prime} \theta+N_{b} \theta \phi^{\prime}+N_{t}\left(\theta^{\prime}\right)^{2}\right) \\
+M^{2}\left(E c_{x}\left(f^{\prime}\right)^{2}+E c_{y}\left(g^{\prime}\right)^{2}\right) \\
+\left(E c_{x}\left(f^{\prime \prime}\right)^{2}+E c_{y}\left(g^{\prime \prime}\right)^{2}\right) \\
+K\left(E c_{x}\left(f^{\prime \prime \prime}\right)^{2}+E c_{y}\left(g^{\prime \prime \prime}\right)^{2}\right) \\
+\left(\left(1+R_{d}\left(1+\left(\theta_{w}-1\right) \theta\right)\right)^{3} \theta^{\prime}\right)^{\prime}=0
\end{array}\right\}
\end{aligned}
$$




$$
\phi^{\prime \prime}+\operatorname{LePr}(f+g) \phi^{\prime}+\left(\frac{N_{t}}{N_{b}}\right) \theta^{\prime \prime}=0
$$

The corresponding boundary conditions are given by

$$
\begin{aligned}
& f=0 g=0 f^{\prime}=1, \\
& g^{\prime}=\lambda \theta=1 N_{b} \phi^{\prime}+N_{t} \theta^{\prime}=0, \\
& a t \eta=0 \\
& f^{\prime} \rightarrow 0 g^{\prime} \rightarrow 0, \\
& \theta \rightarrow 0 \phi \rightarrow 0 \quad \text { as } \rightarrow \rightarrow \infty
\end{aligned}
$$

The skin friction coefficients and Nusselt number are given as

$$
\left.\begin{array}{l}
R e_{x}^{1 / 2} C_{f x}=f^{\prime \prime}(0)-K f^{i v}(0), \\
R e_{y}^{1 / 2} C_{f y}=g^{\prime \prime}(0)-K g^{i v}(0) \\
R e_{x}^{-1 / 2} N u_{x}=-\left(1+R_{d} \theta_{w}^{3}\right) \theta^{\prime}(0), \\
R e_{x}^{-1 / 2} S h_{x}=-\theta^{\prime \prime}(0)\left(\frac{N_{t}}{N_{b}}\right)
\end{array}\right\}
$$

where, $R e_{x}=A_{w} x / v$ read as local Reynolds number.

\section{RESULTS AND DISCUSSION}

The converted Eqns. (11)-(14) with corresponding boundary conditions (15) have been calculated numerically by Runge-Kutta-Fehlberg scheme along with well-known shooting technique. The graphical results are displayed from Figures 2-10 for distinct values of the physical parameters on velocity, temperature and concentration distributions as well as the skin friction coefficient and Nusselt number.

The influence of stretching ratio parameter $\lambda$ is illustrated in Figures 2(a)-2(d). It is noticed that the transverse velocity rises with larger values of $\lambda$ as the stretching velocity in the $y$ direction exceeds that of its counterpart in the $\mathrm{x}$-direction and it is obvious that the $\mathrm{x}$-component of velocity diminishes. $\theta(\eta)$ and $\phi(\eta)$ profiles follow the trend of axial velocity for the same set of values of $\lambda$ and therefore the thermal and solutal boundary layers are thinner. Also, $\lambda=0$, corresponds to $2 \mathrm{D}$ flow analysis and it is pertinent to emphasise that the temperature boundary layer thickness in the case of 2D flow is greater than that of the corresponding case of 3D flow. Moreover, the velocity along $x$-axis for couple stress nanofluid is more comparing to the water nanofluid. These results are useful in high heat transfer experiments in industrial applications.

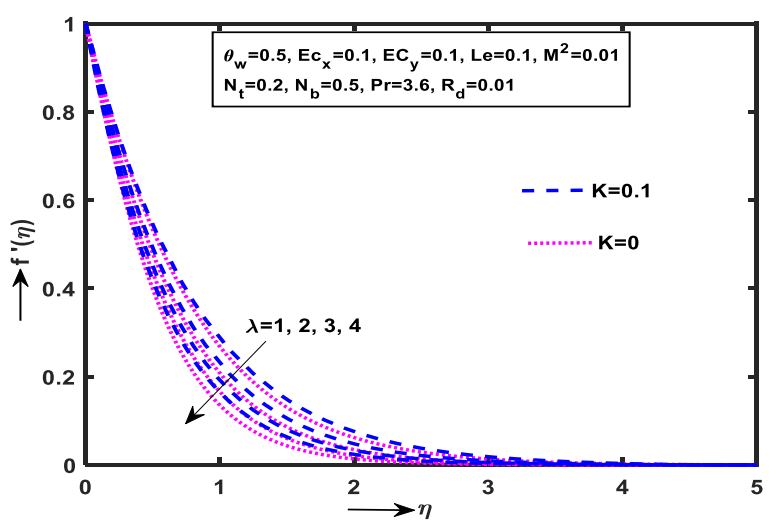

(a)

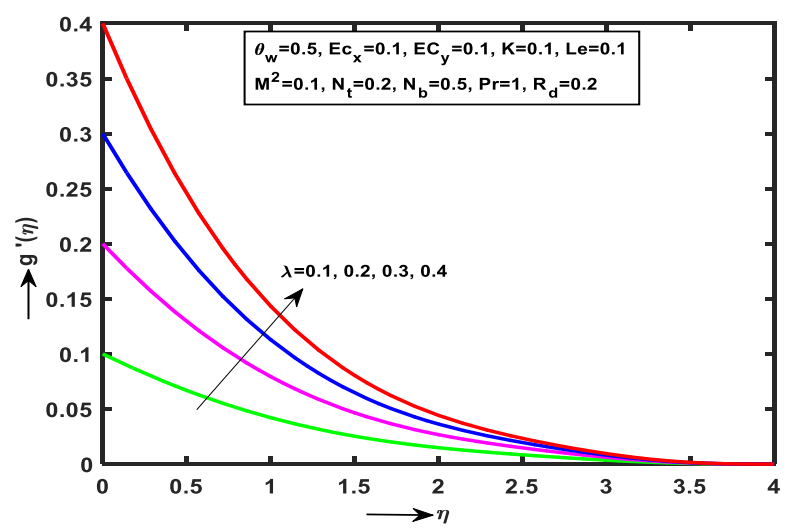

(b)

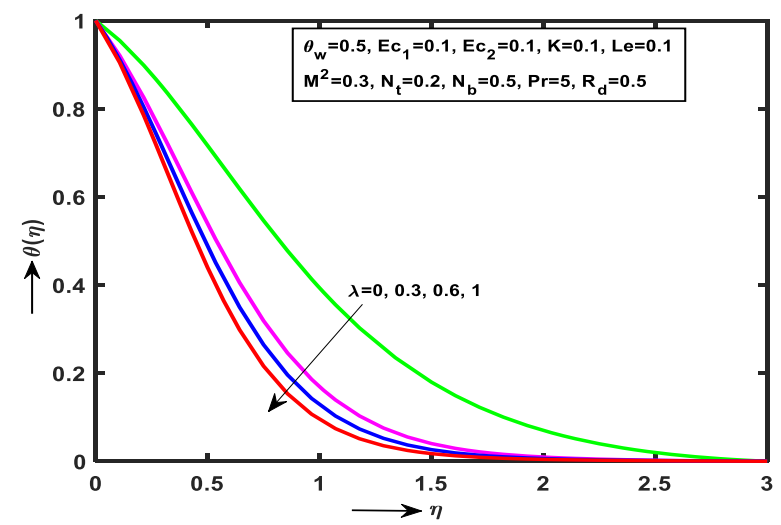

(c)

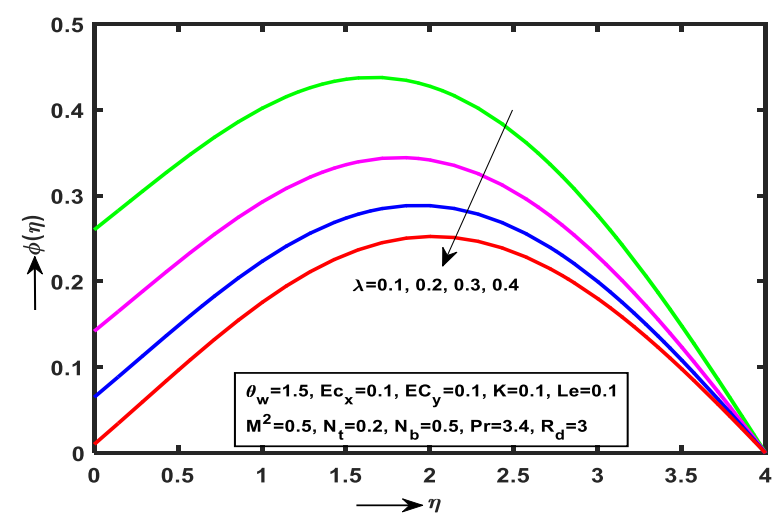

(d)

Figure 2. Influence of $\lambda$ on (a) $f^{\prime}(\eta)$ (b) $g^{\prime}(\eta)$ (c) $\theta(\eta)$ (d) $\phi(\eta)$

Figure 3 signify the influence of Prandtl number Pr on temperature distributions. It is noticed that the thermal boundary layers thickness enhances for smaller Pr values. Physically, the thermal diffusivity of the fluid is higher for smaller Pr and hence thicker thermal boundary layers occur. It is also observed that the temperature distribution in the case of a non-Newtonian fluid is fewer than that of viscous fluid.

Figure 4(a)-(b) exhibit the influence of Eckert number $E c_{x}$ and $E c_{y}$ along $x$ and $y$-directions respectively on $\phi(\eta), \theta(\eta)$. From these figures it is noticed that both $\phi(\eta)$ and $\theta(\eta)$ augmented with an increase in $E c$ along $x$ and $y$-direction. This is due to the frictional force effect in the fluid layers. Also, noticed that the influence of $E c_{x}$ on $\phi(\eta)$ is more than that of $E c_{y}$.

Figures 5(a)-5(b) display the impact of $R_{d}$ (thermal radiations parameter) on temperature $\theta(\eta)$ and concentration $\phi(\eta)$ profiles, respectively. It is pointed out that thickness of the thermal concentration boundary layers increases for 
enhanced values of $R_{d}$ due to the fact that increasing radiation release more thermal energy in the fluid.

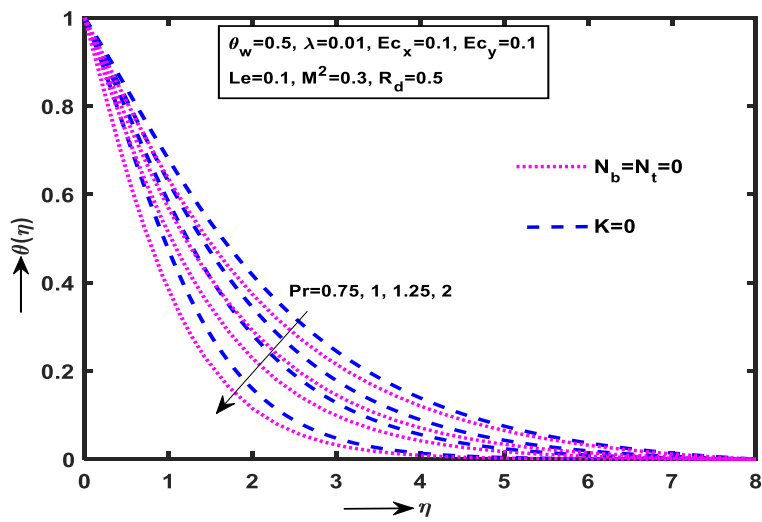

Figure 3. Influence of $\operatorname{Pr}$ on $\theta(\eta)$

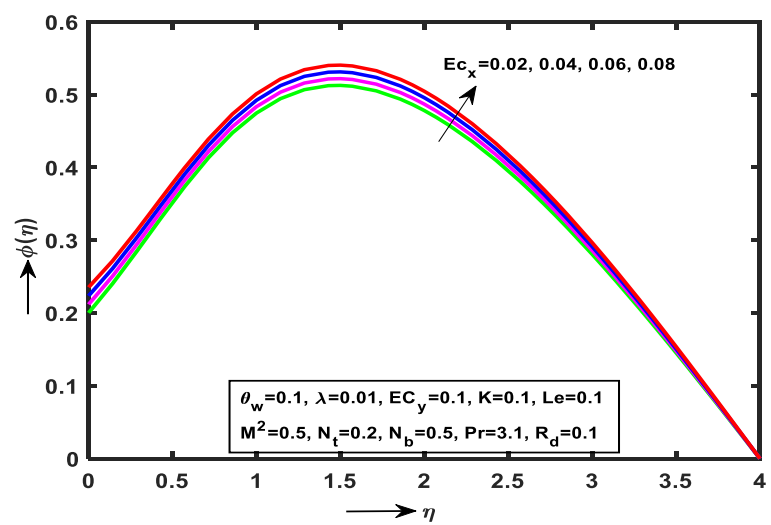

(a)

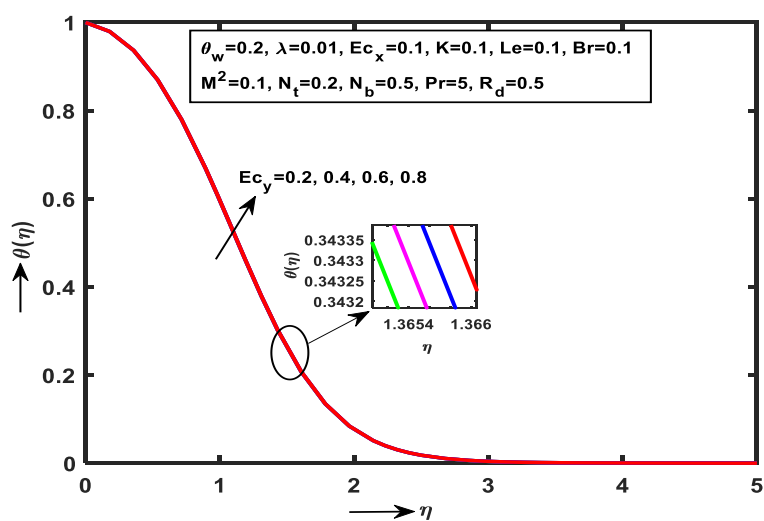

(b)

Figure 4. Influence of (a) $E c_{x}$ on $\phi(\eta)$ (b) $E c_{y}$ on $\theta(\eta)$

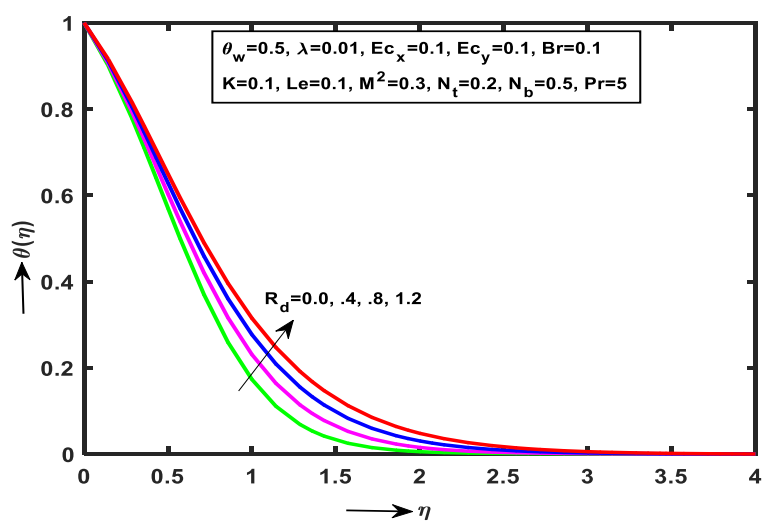

(a)

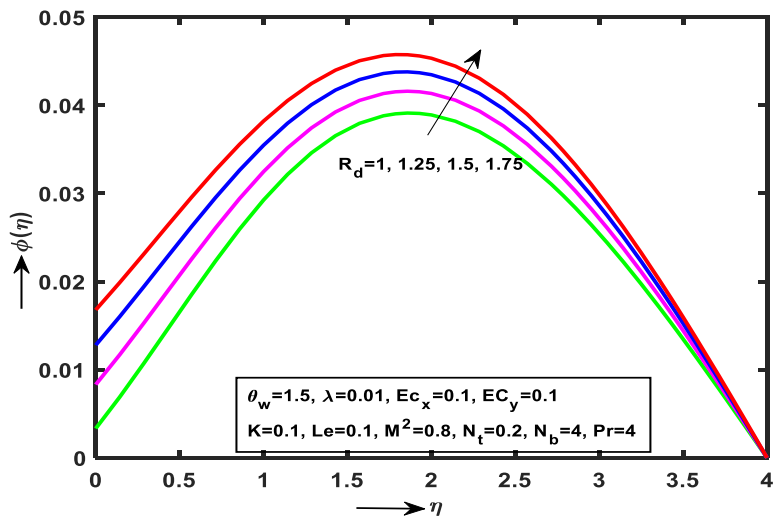

(b)

Figure 5. Influence of $R_{d}$ on (a) $\theta(\eta)$ (b) $\phi(\eta)$

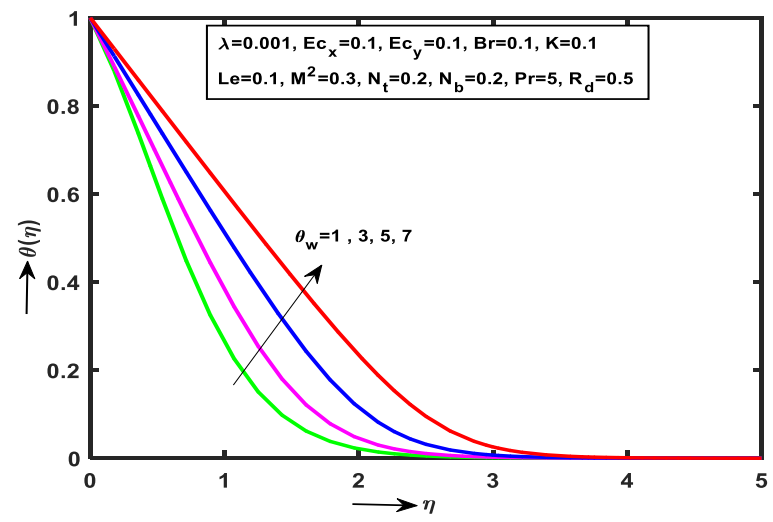

Figure 6. Influence of $\theta_{w}$ on $\theta(\eta)$

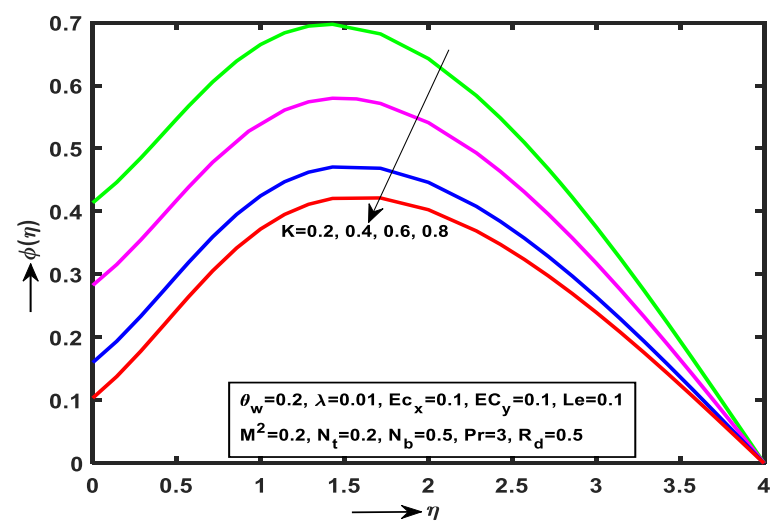

Figure 7. Influence $K$ on $\phi(\eta)$

Figure 6 illustrate the impact of temperature ratio parameter $\theta_{w}$ on $\theta(\eta)$ profile. Presence of $\theta_{w}$ is due to non-linear thermal radiation and its contribution is seen to enhance the thermal energy leading to higher temperatures. Figure 7 depict the couple stress parameter $K$ on the concentration $\phi(\eta)$ distributions respectively. It is noticed that the reduction in temperature profile is observed with enhancing values of couple stress parameter $K$.

Figure 8 expose the variation of thermophoresis parameter $N_{t}$ on $\theta(\eta)$ profile. It is clear that both the profiles $\theta(\eta)$ increase with higher values of $N_{t}$. Physically, increase in thermophoresis parameter $N_{t}$ causes the nanoparticles to move from hotter area to colder area and consequently the temperature and the thermal boundary layer thickness rise. The influence of magnetic field parameter $M^{2}$ on $R e_{x}^{-1 / 2} N u_{x}$ against $\lambda$ is exhibited in Figure 9. It is noticed that the 
$R e_{x}^{-1 / 2} N u_{x}$ rate of heat transfer enhance with increasing values of magnetic field parameter $M^{2}$.

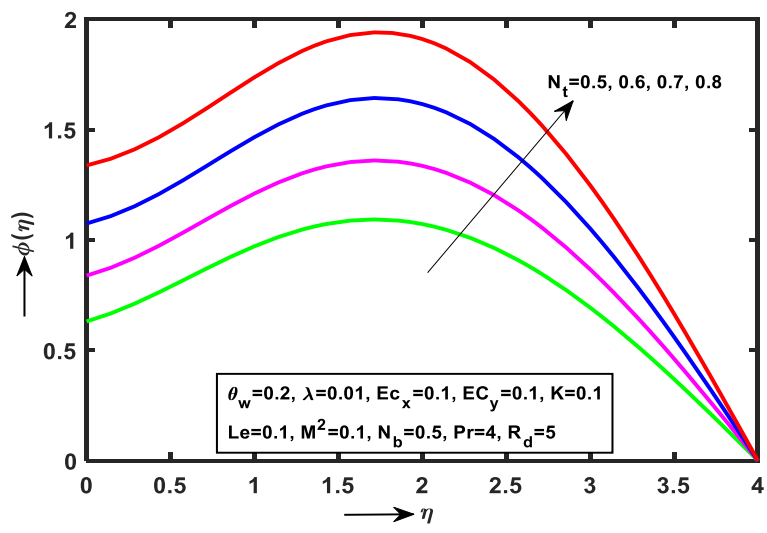

Figure 8. Influence $K$ on $\phi(\eta)$

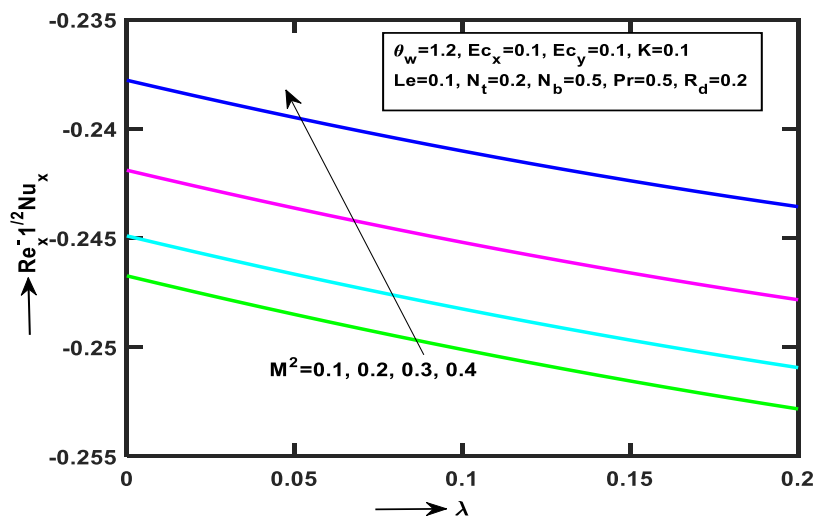

Figure 9. Influence of $M^{2}$ on $R e_{x}^{-1 / 2} N u_{x}$

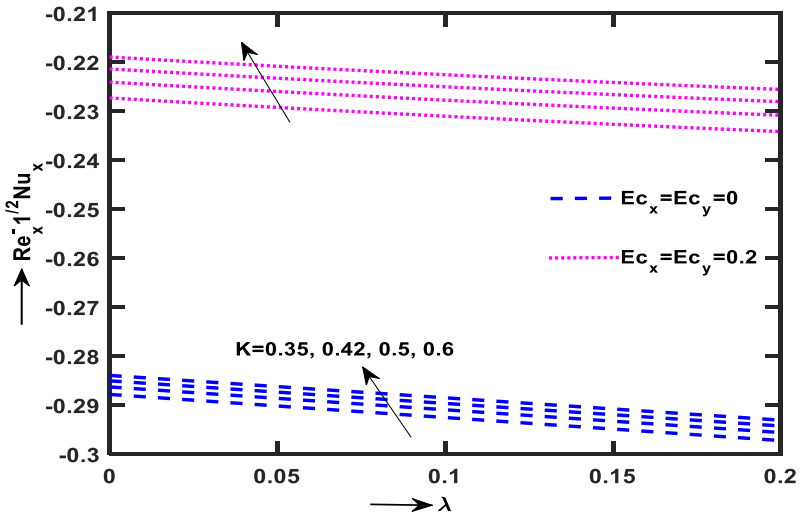

(a)

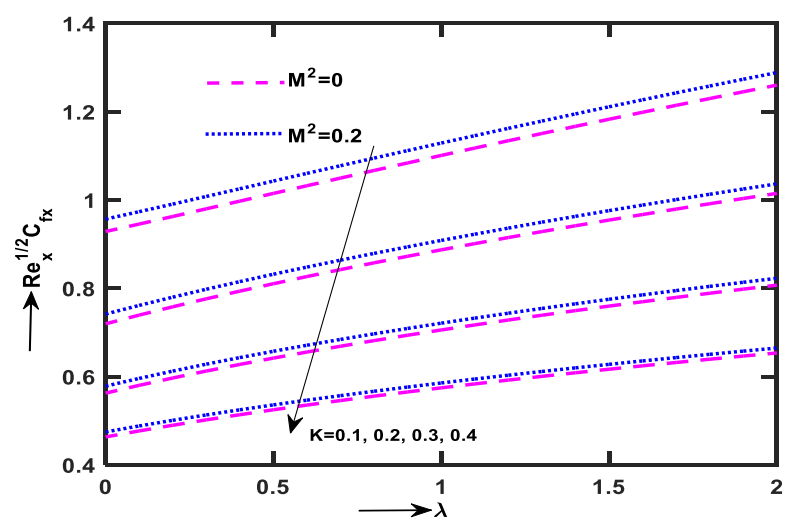

(b)

Figure 10. Influence of $K$ on (a) $\mathrm{Re}_{x}^{-1 / 2} N u_{x}$ (b) $\operatorname{Re}_{x}^{1 / 2} C_{f x}$
Figures 10(a)-10(b) depict the effect $K$ with respect to $\lambda$ on the two components of skin friction coefficients and Nusselt number $R e_{x}^{-1 / 2} N u_{x}$. It is observed that the two components of coefficients of skin friction reduce with K. Also, observed that the skin friction coefficient in the presence of magnetic field $\left(M^{2}=0.2\right)$ is seen to be more than that of the nonmagnetic $\left(M^{2}=0\right)$ case. On the other hand, a reverse trend is observed in the case of rate of heat transfer $R e_{x}^{-1 / 2} N u_{x}$. In the absence of $E c_{x}$ and $E c_{y}$ the present model reduces to the flow model discussed by Hayat et al. [9] and they observed that the rate of heat transfer is seen to be lesser. Hence, it may be concluded that both Joule heating and viscous dissipation are vital in improving the rate of heat transfer of a couple stress nanofluid.

The validity of the current work outcomes of final values are compared with Wang [47] in Table 1. The skin friction coefficient values for $\lambda=0$ compared with those of Oyelakin et al. [48], Nadeem et al. [49], Gupta and Sharma [50], and Ahmad and Nazar [51], respectively in Table 2. The skin friction coefficient values for $\lambda=1$ compared with Nadeem et al. [49] in Table 3. It is observed that the current results are in good agreement with those existing results.

Table 1. Comparison of final values for various values of $\lambda$

\begin{tabular}{ccccc}
\hline & $\begin{array}{c}\text { Previous } \\
\text { Study } \\
\text { Wang [47] } \\
f(\infty)\end{array}$ & $\begin{array}{c}\text { Present } \\
\text { study } \\
f(\infty)\end{array}$ & $\begin{array}{c}\text { Previous } \\
\text { Study } \\
\text { Wang [47] }\end{array}$ & $\begin{array}{c}\text { Present } \\
\text { study } \\
g(\infty)\end{array}$ \\
\hline $\mathbf{0 . 0 0}$ & 1.000000 & 1.00000 & 0.000000 & 0.00000 \\
$\mathbf{0 . 2 5}$ & 0.907075 & 0.90707 & 0.257986 & 0.25798 \\
$\mathbf{0 . 5 0}$ & 0.842360 & 0.84236 & 0.451671 & 0.45167 \\
$\mathbf{0 . 7 5}$ & 0.792308 & 0.79230 & 0.612049 & 0.61212 \\
$\mathbf{1 . 0 0}$ & 0.751527 & 0.75152 & 0.751527 & 0.75148 \\
\hline
\end{tabular}

Table 2. Comparison of $-f^{\prime \prime}(0)$ (Skin friction coefficient) for various values of $M$ for $\lambda=0$

\begin{tabular}{cccccc}
\hline$M$ & $\begin{array}{c}\text { Present } \\
\text { study } \\
-f^{\prime \prime}(0)\end{array}$ & $\begin{array}{c}\text { Oyelakin } \\
\text { et al. [48] }\end{array}$ & $\begin{array}{c}\text { Nadeem } \\
\text { et al. } \\
{[\mathbf{4 9 ]}}\end{array}$ & $\begin{array}{c}\text { Gupta } \\
\text { and } \\
\text { Sharma } \\
{[\mathbf{5 0}]}\end{array}$ & $\begin{array}{c}\text { Ahmad } \\
\text { and } \\
\text { Nazar } \\
{[\mathbf{5 1}]}\end{array}$ \\
\hline 0.0 & 1.00000 & 1.0000 & 1.0004 & 1.0003 & 1.0042 \\
10 & 3.31662 & 3.31662 & 3.3165 & 3.3165 & 3.3165 \\
100 & 10.04987 & 10.04987 & 10.049 & 10.0498 & 10.049 \\
\hline
\end{tabular}

Table 3. Comparison of $-f^{\prime \prime}(0)$ (Skin friction coefficient) with various values of $M$ for $\lambda=1$

\begin{tabular}{ccc}
\hline \multirow{2}{*}{$M$} & $\begin{array}{c}\text { Present Study } \\
-f^{\prime \prime}(0)\end{array}$ & $\begin{array}{c}\text { Nadeem et al. [49] } \\
-f^{\prime \prime}(0)\end{array}$ \\
\hline 0.0 & 1.1737 & 1.1737 \\
10 & 3.3672 & 3.3667 \\
100 & 10.0664 & 10.066 \\
\hline
\end{tabular}

\section{CONCLUSIONS}

This article deals with the steady MHD 3D flow of a couple stress nanofluid caused due to a sheet stretching. The dimensionless equations are derived and solved computationally. The major conclusions in the current study are indicated here under:

$>$ The Eckert number is seen to have significant influence on temperature. The velocity of the couple stress fluid in the presence of stretching ratio 
parameter is additional than that of a viscous fluid.

$>$ The temperature of the couple stress fluid in the presence of Prandtl number is lower than that of a viscous fluid. Viscous dissipation boosted the rate of heat transfer.

\section{REFERENCES}

[1] Ashraf, M.B., Alsaedi, A., Hayat, T., Shehzad, S.A. (2017). Convective heat and mass transfer in threedimensional mixed convection flow of viscoelastic fluid in presence of chemical reaction and heat source/sink. Computational Mathematics and Mathematical Physics, 57(6):

1066-1079. https://doi.org/10.1134/S0965542517060021

[2] Mohamed, M.K.A., Noar, N.A.Z., Salleh, M.Z., Ishak, A. (2017). Slip flow on stagnation point over a stretching sheet in a viscoelastic nanofluid. In AIP Conference Proceedings, 1830(1): https://doi.org/10.1063/1.4980878

[3] Rana, P., Bhargava, R., Anwar Bég, O., Kadir, A. (2017). Finite element analysis of viscoelastic nanofluid flow with energy dissipation and internal heat source/sink effects. International Journal of Applied and Computational Mathematics, 2(2): 1421-1447. https://doi.org/10.1007/s40819-016-0184-5

[4] Seth, G.S., Sharma, R., Mishra, M.K., Chamkha, A.J. (2017). Analysis of hydromagnetic natural convection radiative flow of a viscoelastic nanofluid over a stretching sheet with Soret and Dufour effects. Engineering Computations, 34(2): 603-628. https://doi.org/10.1108/EC-10-2015-0290

[5] Hayat, T., Aziz, A., Muhammad, T., Alsaedi, A. (2017). Model and comparative study for flow of viscoelastic nanofluids with Cattaneo-Christov double diffusion. PLOS ONE, 12(1): 1-19. https://doi.org/10.1371/journal.pone.0168824

[6] Kumar, K.G., Gireesha, B.J., Manjunatha, S. Rudraswamy, N.G. (2017). Effect of nonlinear thermal radiation on double-diffusive mixed convection boundary layer flow of viscoelastic nanofluid over a stretching sheet. International Journal of Mechanical and $\begin{array}{lll}\text { Materials } & \text { Engineering, } & 12(1):\end{array}$ https://doi.org/10.1186/s40712-017-0083-5

[7] Kumar, K.G., Rudraswamy, N.G., Gireesha, B.J., Krishnamurthy, M.R. (2017). Influence of nonlinear thermal radiation and viscous dissipation on threedimensional flow of Jeffrey nano fluid over a stretching sheet in the presence of Joule heating. Nonlinear Engineering, 6(3): 207-219. https://doi.org/10.1515/nleng-2017-0014

[8] Satyanarayana, P.V., Tarakaramu, N., Akshit, S.M., Ghori, J.P. (2017). MHD flow and heat transfer of an Eyring-Powell fluid over a linear stretching sheet with viscous dissipation-a numerically study. Frontiers Heat Mass Transfer, 9(9): 1-5. https://doi.org/10.5098/hmt.9.9

[9] Hayat, T., Muhammad, T., Alsaedi, A., Alhuthali, M.S. (2015). Magnetohydrodynamic three-dimensional flow of viscoelastic nanofluid in the presence of nonlinear thermal radiation. Journal of Magnetism and Magnetic Materials, 385: 222-229. https://doi.org/10.1016/j.jmmm.2015.02.046

[10] Zhang, X.H., Xia, Y.M., Zeng, G.Y., Tan, Q., Guo, B.
(2018). Numerical and experimental investigation of rock breaking method under free surface by TBM disc cutter. Journal of Central South University, 25(9): 21072118. https://doi.org/10.1007/s11771-018-3900-y

[11] Xiang, J., Zhang, C., Zhou, C., Liu, G., Zhou, W. (2018). Heat transfer performance testing of a new type of phase change heat sink for high power light emitting diode. Central South University, 25(7): 1708-1716. https://doi.org/10.1007/s11771-018-3862-0

[12] Animasaun, I.L., Prakash, J., Vijayaragavan, R., Sandeep, N. (2017). Stagnation flow of nanofluid embedded with dust particles over an inclined stretching sheet with induced magnetic field and suction. Journal of Nanofluids, $\quad 6(1)$ : 28-37. https://doi.org/10.1166/jon.2017.1308

[13] He, Q., Huang, J., Shi, X., Wang, X.P., Bi, C. (2017). Numerical simulation of $2 \mathrm{D}$ unsteady shear-thinning non-Newtonian incompressible fluid in screw extruder with fictitious domain method. Computers \& Mathematics with Applications, 73(1): 109-121. https://doi.org/10.1016/j.camwa.2016.11.005

[14] Tarakaramu, N., Satyanarayana, P.V. (2019). Nonlinear thermal radiation and joule heating effects on MHD stagnation point flow of nanofluid over a convectively heated stretching surface. Journal of Nanofluids, 8(5): 1066-1075. https://doi.org/10.1166/jon.2019.1651

[15] Kumar, K.G., Ramesh, G.K., Gireesha, B.J., Gorla, R.S.R. (2018). Characteristics of Joule heating and viscous dissipation on three-dimensional flow of Oldroyd B nanofluid with thermal radiation. Alexandria Engineering Journal, 57(3): 2139-2149. https://doi.org/10.1016/j.aej.2017.06.006

[16] Rehman, K.U., Khan, A.A., Malik, M.Y., Makinde, O.D. (2017). Thermophysical aspects of stagnation point magnetonanofluid flow yields by an inclined stretching cylindrical surface: A non-Newtonian fluid model. Journal of the Brazilian Society of Mechanical Sciences and Engineering, 39(9): 3669-3682. https://doi.org/10.1007/s40430-017-0860-3

[17] Babu, D.H., Narayana, P.S. (2016). Joule heating effects on MHD mixed convection of a Jeffrey fluid over a stretching sheet with power law heat flux: A numerical study. Journal of Magnetism and Magnetic Materials, 412:

185-193. https://doi.org/10.1016/j.jmmm.2016.04.011

[18] Amiri, D.A., Kayhani, M.H., Nazari, M. (2017). Simulation of particle motion in Non-Newtonian fluids by immersed boundary-lattice Boltzmann method. J. Applied Computational Sciences Mech., 28(1): 75-92.

[19] Rashidi, M.M., Bagheri, S., Momoniat, E., Freidoonimehr, N. (2017). Entropy analysis of convective MHD flow of third grade non-Newtonian fluid over a stretching sheet. Ain Shams Engineering Journal, $\quad 8(1)$ : 77-85. https://doi.org/10.1016/j.asej.2015.08.012

[20] Pourmehran, O., Rahimi-Gorji, M., Tavana, M., Bandpy, M.G., Ganji, D.D. (2017). Heat transfer investigation of non-Newtonian fluid between two vertically infinite flat plates by numerical and analytical solutions. Annals Biomedical Science Eng., 1: 1-11. https://doi.org/10.29328/journal.hbse.1001001

[21] Sheikholeslami, M., Shehzad, S.A. (2017). RETRACTED: Magnetohydrodynamic nanofluid convective flow in a porous enclosure by means of LBM. 
International Journal of Heat and Transfer, 113: 796-805. https://doi.org/10.1016/j.ijheatmasstransfer.2017.05.130

[22] Animasaun, I.L., Mahanthesh, B., Jagun, A.O., Bankole, T.D., Sivaraj, R., Shah, N.A., Saleem, S. (2019). Significance of Lorentz force and thermoelectric on the flow of $29 \mathrm{~nm} \mathrm{CuO-water} \mathrm{nanofluid} \mathrm{on} \mathrm{an} \mathrm{upper}$ horizontal surface of a paraboloid of revolution. Journal $\begin{array}{llll}\text { of } \quad \text { Heat } & \text { Transfer, } & \text { 141(2): }\end{array}$ https://doi.org/10.1115/1.4041971

[23] Mahanthesh, B., Gireesha, B.J., Gorla, R.S., Makinde, O.D. (2018). Magnetohydrodynamic three-dimensional flow of nanofluids with slip and thermal radiation over a nonlinear stretching sheet: A numerical study. Neural Computing and Applications, 30(5): 1557-1567. https://doi.org/10.1007/s00521-016-2742-5

[24] Stokes, V.K. (2004). Couple stresses in fluids. The Physics of Fluids, 9(9): 1709-1715. https://doi.org/10.1063/1.1761925

[25] Stokes, V.K. (1984). Theories of Fluids with Microstructure: an introduction, Springer-Verlag. Berlin Heidelberg New York, 1-210. https://doi.org/10.1007/978-3-642-82351-0

[26] Eringen, A.C. (1966). Theory of micropolar fluids. Journal of Mathematics and Mechanics, 1-18.

[27] Hayat, T., Muhammad, T., Alsaedi, A., Alhuthali, M.S. (2015). MHD three-dimensional flow of viscoelastic nanofluid in the presence of nonlinear thermal radiation. Journal of Magnetism and Magnetic Materials, 385: 222229. https://doi.org/10.1016/j.jmmm.2015.02.046

[28] Turkyilmazoglu, M. (2014). Exact solutions for twodimensional laminar flow over a continuously stretching or shrinking sheet in an electrically conducting quiescent couple stress fluid. International Journal of Heat Mass Transfer, 72: 1-8 https://doi.org/10.1016/j.ijheatmasstransfer.2014.01.009

[29] Kaladhar, K., Motsa, SS., Srinivasacharya, D. (2015). Thermal radiation and diffusion effects on natural convection flow of couple stress fluid in a vertical channel. Progress Computational Fluid Dynamics, 15(6): 1-8. https://doi.org/10.1504/PCFD.2015.072775

[30] Hayat, T., Muhammad, T., Ali Shehzad, S., Alsaedi, A. (2017). Simultaneous effects of magnetic field and convective condition in three-dimensional flow of couple stress nanofluid with heat generation/absorption. Journal of the Brazilian Society of Mechanical Sciences and Engineering, $\quad 39(4)$ : 1165-1176. https://doi.org/10.1007/s40430-016-0632-5

[31] Beg, O.A., Ghosh, S.K., Beg, T. (2012). Mathematical modeling of oscillatory magneto-convection of a couplestress biofluid in an inclined rotating channel. Journal of Mechanics in Medicine and Biology, 12(03): 1-35. https://doi.org/10.1142/S0219519411004654

[32] Hayat, T., Hussain, S., Muhammad, T., Alsaedi, A., Ayub, M. (2017). Radiative flow of Powell-Eyring nanofluid with convective boundary conditions. Chinese Journal of Physics, 55(4): 1523-1538. https://doi.org/10.1016/j.cjph.2017.05.009

[33] Kumar, N.R., Bhramara, P., Sundar, L.S., Singh, M.K., Sousa, A.C. (2017). Heat transfer, friction factor and effectiveness of $\mathrm{Fe}_{3} \mathrm{O}_{4}$ nanofluid flow in an inner tube of double pipe U-bend heat exchanger with and without longitudinal strip inserts. Experimental Thermal and Fluid Science, 331-343 https://doi.org/10.1016/j.expthermflusci.2017.03.019
[34] Ellahi, R., Bhatti, M.M., Khalique, C.M. (2017). Threedimensional flow analysis of Carreau fluid model induced by peristaltic wave in the presence of magnetic field. Journal of Molecular Liquids, 24: 1059-1068. https://doi.org/10.1016/j.molliq.2017.06.082

[35] Narayana, P.V., Tarakaramu, N., Makinde, O.D., Venkateswarlu, B., Sarojamma, G. (2018). MHD stagnation point flow of viscoelastic nanofluid past a convectively heated stretching surface. Defect and Diffusion Forum, 387: 106-120. https://doi.org/10.4028/www.scientific.net/DDF.387.10 6

[36] Tamoor, M., Waqas, M., Khan, M.I., Alsaedi, A., Hayat, T. (2017). Magnetohydrodynamic flow of Casson fluid over a stretching cylinder. Results in Physics, 7: 498-502. https://doi.org/10.1016/j.rinp.2017.01.005

[37] Hayat, T., Muhammad, B.T., Shehzad, S.A., Alsaedib, A. (2017). Three-dimensional rotating flow of Maxwell nanofluid. Journal of Molecular Liquids, 229: 495-500. https://doi.org/10.1016/j.molliq.2016.12.095

[38] Ramzan, M. (2015). Influence of Newtonian heating on three dimensional MHD flow of couple stress nanofluid with viscous dissipation and joule heating. PLOS ONE, 10(4):

$1-24$. https://doi.org/10.1371/journal.pone.0124699

[39] Adesanya, S.O., Makinde, O.D. (2015). Effects of couple stresses on entropy generation rate in a porous channel with convective heating. Computational and Applied Mathinde, 34(1): 293-307. https://doi.org/10.1007/s40314-014-0117-z

[40] Ullah, I., Shafie, S., Makinde, O.D., Khan, I. (2017). Unsteady MHD Falkner-Skan flow of Casson nanofluid with generative/destructive chemical reaction. Chemical Eng. $\quad$ Science, 172: 694-706. https://doi.org/10.1016/j.ces.2017.07.011

[41] Eid, M.R., Makinde, O.D. (2018). Solar radiation effect on a magneto nanofluid flow in a porous medium with chemically reactive species. International Journal of Chemical Reactor Engneering, 16(9). https://doi.org/10.1515/ijcre-2017-0212

[42] Zeng, W., Yang, S., Tian, W., Wen, K. (2018). Numerical investigation on permeability evolution behavior of rock by an improved flow-coupling algorithm in particle flow code. Central South University, 25(6): 1367-1385. https://doi.org/10.1007/s11771-0183833-5

[43] Makinde, O.D., Khan, W.A., Khan, Z.H. (2017). Stagnation point flow of MHD chemically reacting nanofluid over a stretching convective surface with slip and radiative heat. Proceedings of the Institution of Mechanical Engineers. Part E, Journal of Process Mechanical Engineering, 231(4): 695-703. https://doi.org/10.1177/0954408916629506

[44] Makinde, O.D., Mabood, F., Khan, W.A., Tshehla, M.S. (2016). MHD flow of a variable viscosity nanofluid over a radially stretching convective surface with radiative heat. Journal of Molecular Liquids, 219: 624-630. https://doi.org/10.1016/j.molliq.2016.03.078

[45] Satyanarayana, P.V. (2017). Lie group analysis for the flow and heat transfer of a nanofluid over a stretching sheet with viscous dissipation. Journal of Nanofluids, 6(6): 1181-1187. https://doi.org/10.1166/jon.2017.1395

[46] Brewster, M.Q. (1992). Thermal Radiative Transfer Properties. A Wiley-Intersciences Publication, New 
York, 1-317.

[47] Wang, C.Y. (1984). The three-dimensional flow due to a stretching flat surface. Physics of Fluids, 27(8): 1-4. https://doi.org/10.1063/1.864868

[48] Oyelakin, I.S., Mondal, S., Sibanda, P. (2016). Unsteady Casson nanofluid flow over a stretching sheet with thermal radiation, convective and slip boundary conditions. Alexandria Engineering Journal, 55(2): 1025-1035. https://doi.org/10.1016/j.aej.2016.03.003

[49] Nadeem, S., Haq, R.U., Akbar, N.S. (2014). MHD threedimensional boundary layer flow of Casson nanofluid past a linearly stretching sheet with convective boundary condition. IEEE Transactions Nanotechnology, 13(1): 109-115. https://doi.org/10.1109/TNANO.2013.2293735

[50] Gupta, S., Sharma, K. (2017). Numerical simulation for magnetohydrodynamic three dimensional flow of Casson nanofluid with convective boundary conditions and thermal radiation. Engineering Computations, 34(8): 113. https://doi.org/10.1108/EC-02-2017-0064

[51] Ahmad, K., Nazar, R. (2011). Magnetohydrodynamic three-dimensional flow and heat transfer over a stretching surface in a viscoelastic fluid is discussed. Journal of Science and Technology, 3(1): 33-46.

\section{NOMENCLATURE}

$\begin{array}{ll}(x, y) & \text { Cartesian coordinate's } \\ A, B, C & \text { velocity components along } \mathrm{x}, \mathrm{y}, \mathrm{z} \text {-axis } \\ \Psi & \text { volume fraction of nanoparticle } \\ c_{f} & \text { Skin friction coefficient } \\ c_{p} & \text { Specific heat } \\ c_{\infty} & \text { Uniform ambient concentration } \\ D_{0} & \text { Brownian diffusion } \\ D_{\Theta} & \text { Thermophoresis diffusion } \\ E c_{x} & \text { Eckert number in the direction of } \mathrm{x} \\ & =\frac{2 A_{w}^{2}}{\left(c_{p}\right)_{f}\left(\Theta_{w}-\Theta_{\infty}\right)}\end{array}$

$E c_{y} \quad$ Eckert number in the direction of $\mathrm{y}$

$$
=\frac{2 B_{w}^{2}}{\left(c_{p}\right)_{f}\left(\Theta_{w}-\Theta_{\infty}\right)}
$$

$\begin{array}{ll}f & \text { Dimensionless stream function } \\ f^{\prime} & \text { Dimensionless velocity } \\ k^{*} & \text { Mean absorption coefficient } \\ k & \text { Thermal conductivity } \\ K & \text { Couple Stress Parameter }=a v^{\prime} / v^{2}\end{array}$

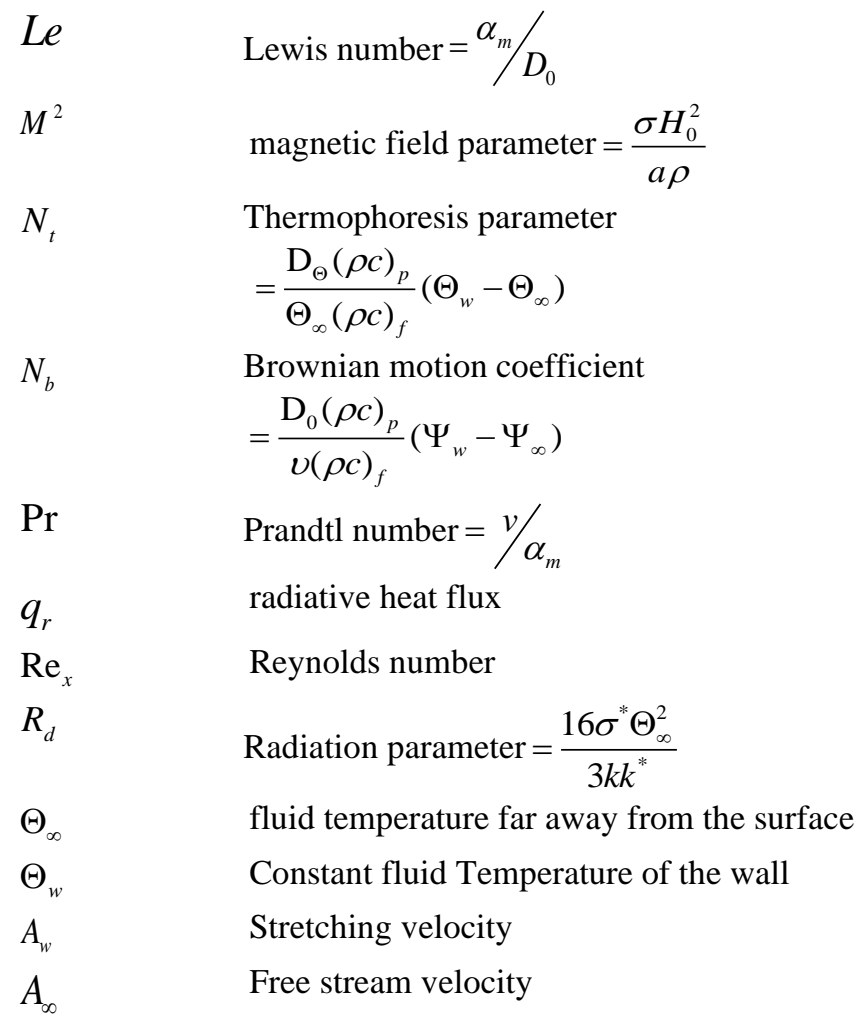

\section{Greek symbols}

$\begin{array}{ll}\alpha_{m} & \text { Thermal diffusion } \\ \mu & \text { Dynamic viscosity } \\ \phi & \text { Dimensionless concentration } \\ \lambda & \text { Ratio parameter }=b / a \\ v & \text { Kinematic viscosity } \\ \sigma & \text { Electrical conductivity } \\ \theta & \text { Dimensionless temperature } \\ \alpha_{m} & \text { Base fluid thermal diffusivity }=k /\left(\rho c_{p}\right)_{f} \\ v^{\prime} & \text { Couple stress viscosity }=\mu / \rho \\ \xi & \text { Ratio of the nanoparticle to the fluid } \\ & (\rho c)_{p} /(\rho c)_{f} \\ (\rho c)_{f} & \text { Heat capacity of the fluid } \\ (\rho c)_{p} & \text { Heat capacity of the nanoparticle to the fluid } \\ \rho_{f} & \text { Fluid density } \\ \rho & \text { Density } \\ \sigma^{*} & \text { Boltzmann constant }\end{array}$

\section{Subscripts}

condition at free stream 